\title{
Clinical Characteristics of Rhabdomyosarcoma in Children: A 4-Year Study in A Tertiary Hospital in Indonesia
}

\author{
Lelani Reniarti, ${ }^{1}$ Nur Fatharani, ${ }^{2}$ Nur Suryawan ${ }^{1}$ \\ ${ }^{1}$ Department of Child Health Faculty of Medicine Universitas Padjadjaran/Dr. Hasan Sadikin \\ General Hospital Bandung, Indonesia, ${ }^{2}$ Faculty of Medicine Universitas Padjadjaran, Indonesia
}

\section{Abstract}

Background: Rhabdomyosarcoma (RMS) is the most common soft-tissue sarcomas (STS) in children. Even though the survival rate has increased, the mortality rates remain significantly higher in developing countries due to delay in diagnosis contributed by its diverse and clinical manifestations. This study aimed to describe the clinical characteristics of RMS patients at the Department of Child Health, Dr. Hasan Sadikin General Hospital, Bandung, Indonesia.

Methods: A descriptive cross-sectional retrospective study was conducted using a total sampling method on medical records of RMS patients aged $\leq 18$-year-old during a 4-year period (2015-2018). Data on patient demographics, clinical manifestations, biopsy procedure, histopathological subtype, tumor size, primary site, pre-treatment staging, and treatment were reviewed and presented.

Results: Of 30 data retrieved, male (57\%), aged 1 to 5-year-old (47\%), and diagnosed through open biopsy $(63 \%)$ comprised the majority of the patients. More than half of the patients came with advanced stage of the disease $(80 \%)$ and were treated with chemotherapy (83\%). Most RMS patients had a tumor located in the head and neck region (40\%) with a size of $>5 \mathrm{~cm}(70 \%)$ and embryonal subtypes (43\%). The remaining patients experienced alveolar subtype (17\%), spindle cell subtype $(13 \%)$, and unknown subtype (27\%) of RMS.

Conclusions: Children with a tumor in the head and neck region should be suspected as rhabdomyosarcoma, as there are various clinical characteristics of RMS in children found in this study.

Keywords: Clinical characteristics, primary site, rhabdomyosarcoma

\section{Introduction}

Rhabdomyosarcoma (RMS) is the most common soft-tissue sarcomas (STS) and the third most common solid extracranial tumor in children. ${ }^{1,2}$ Incidence of RMS in India accounts for around 1 to $4.5 \%$ of all malignancies in children. ${ }^{3}$ Each year, approximately 350 children are diagnosed with RMS in the United States, ${ }^{4}$ while in Jakarta, Indonesia, the study has shown that there are only 44 RMS cases in 8-years time and 11 RMS cases in 4 years at Dr. Cipto Mangunkusumo General Hospital and Dharmais Cancer Hospital, respectively.,6

RMS is originated from embryonic mesenchyme that differentiates into striated or skeletal muscle. ${ }^{7}$ Therefore, RMS could rise anywhere throughout the human body where there is skeletal muscle or not such as the urinary bladder, bile ducts, etc. ${ }^{8}$ The symptoms are not always in the form of a lump. The clinical presentations depend on the primary location of the tumor where the majority of symptoms are related to the compression of local structures by the masses and may cause organ-specific symptoms. ${ }^{8}$ This non-specific pattern could complicate RMS detection and cause a diagnostic delay. ${ }^{1,9}$ Survival rate of children with RMS has increased from 25\% in 1970 to $70 \%$ in 2001 . However, mortality rates remain significantly higher in developing countries than in developed countries. This may also be attributable to the high frequency of detection and diagnostic delays among them. ${ }^{10}$

Currently, research and literature studies on the clinical characteristics of rhabdomyosarcoma in Indonesia are very limited. This study aimed to describe the clinical characteristics of rhabdomyosarcoma in children admitted at Dr. Hasan Sadikin General Hospital, Bandung. 


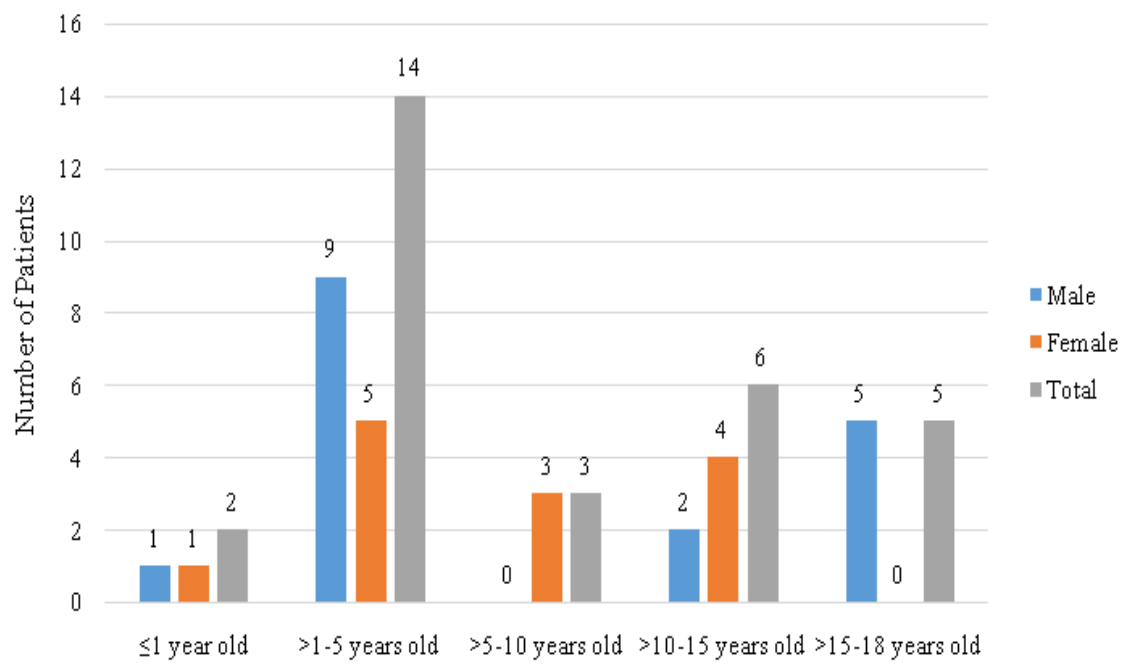

Figure Age of Children with Rhabdomyosarcoma

\section{Methods}

This study was performed at Dr. Hasan Sadikin General Hospital, a tertiary hospital in Bandung, West Java, Indonesia using a descriptive cross-sectional design and total sampling method. A retrospective analysis was performed on medical records of children $(n=40)$ who were diagnosed with RMS through biopsy during the period of 2015-2018. Incomplete medical records were excluded $(\mathrm{n}=10)$. The medical records were reviewed for patient identities, clinical manifestations, biopsy procedure, histopathological subtype, tumor size, primary site, TNM staging, and treatment.

Tumor size had been used in evaluation for pre-treatment TNM staging according to Children's Oncology Group Soft-Tissue Sarcoma Committee's (COG-STS). ${ }^{11}$ The histological subtype classification used in this study was based on the newest classification

Table 1 Clinical Manifestations of Children with Rhabdomyosarcoma

\begin{tabular}{lcc}
\hline \multicolumn{1}{c}{ Clinical Manifestations } & n & \% \\
\hline Painless mass/lump/swelling & 24 & 80 \\
Local pain & 3 & 10 \\
Proptosis & 3 & 10 \\
Ophthalmoplegia & 1 & 3 \\
Spontaneous bleeding & 3 & 10 \\
Epistaxis & 1 & 3 \\
Nasal congestion & 1 & 3 \\
Vomiting & 1 & 3 \\
Urinary obstruction & 1 & 3 \\
Convulsions & 1 & 3 \\
Pale & 2 & 7 \\
Limb weakness & 2 & 7 \\
\hline
\end{tabular}


Table 2 Clinical Characteristics of Childhood Rhabdomyosarcoma

\begin{tabular}{|c|c|c|}
\hline Clinical Characteristics & $\mathbf{N}$ & $\%$ \\
\hline \multicolumn{3}{|l|}{ Gender } \\
\hline Male & 17 & 57 \\
\hline Female & 13 & 43 \\
\hline \multicolumn{3}{|l|}{ Age (years old) } \\
\hline$\leq 1$ & 2 & 7 \\
\hline$>1-5$ & 14 & 47 \\
\hline$>5-10$ & 3 & 10 \\
\hline$>10-15$ & 6 & 20 \\
\hline$>15-18$ & 5 & 17 \\
\hline \multicolumn{3}{|l|}{ Biopsy procedure } \\
\hline Open biopsy & 19 & 63 \\
\hline FNAB & 11 & 37 \\
\hline \multicolumn{3}{|l|}{ Tumor size } \\
\hline$\leq 5 \mathrm{~cm}$ & 6 & 20 \\
\hline$>5 \mathrm{~cm}$ & 21 & 70 \\
\hline Not specified & 3 & 10 \\
\hline \multicolumn{3}{|l|}{ Histopathological subtype } \\
\hline Embryonal & 13 & 43 \\
\hline Alveolar & 5 & 17 \\
\hline Spindle cell & 4 & 13 \\
\hline Not specified & 8 & 27 \\
\hline \multicolumn{3}{|l|}{ Primary site } \\
\hline Head and neck & 12 & 40 \\
\hline Trunk & 5 & 17 \\
\hline Urogenital tract & 5 & 17 \\
\hline Extremities & 8 & 27 \\
\hline \multicolumn{3}{|l|}{ TNM Staging } \\
\hline II & 1 & 3 \\
\hline III & 6 & 20 \\
\hline IV & 18 & 60 \\
\hline Not specified & 5 & 17 \\
\hline \multicolumn{3}{|l|}{ Treatment } \\
\hline Operation & 1 & 3 \\
\hline Chemotherapy & 14 & 47 \\
\hline Operation-Chemotherapy & 10 & 33 \\
\hline Operation-Radiation & 1 & 3 \\
\hline Chemotherapy-Radiation & 1 & 3 \\
\hline Not given & 3 & 10 \\
\hline
\end{tabular}


from WHO (2013). ${ }^{12}$ Pre-treatment staging used a modified TNM system based on the primary site, either favorable or unfavorable site. ${ }^{7}$

This study was approved by the Research Ethics Committee of Universitas Padjadjaran and Dr. Hasan Sadikin General Hospital. Further acknowledgment had been received by the Department of Child Health and the Department of Anatomical Pathology Dr. Hasan Sadikin General Hospital. The data collected were analyzed using descriptive statistics and then presented by using tables and charts (Microsoft ${ }^{\circledR}$ Excel 2016 and IBM ${ }^{\circledR}$ SPSS $®$ version 20 ).

\section{Results}

A total of 30 children with confirmed RMS by biopsy were included during the 4-year study period. The median aged was 5 years old (range; 9 months to 18 years old). The highest incidence occurred in the age group of 1-5 years (Figure). Male patients outnumbered female patients with $\mathrm{M}: \mathrm{F}$ ratio $1.3: 1$. Patient demographics and tumor characteristics were summarized in Table 2 . While the majority of the patients complained about a painless mass in their body, some patients came with other signs related to the primary site (Table 1 ).

Tumor size was assessed in 27 patients only, of whom 21 patients with tumor $>5 \mathrm{~cm}$. Biopsy was performed in open biopsy $(n=19$; $63 \%$ ) or fine-needle aspiration biopsy (11; $37 \%$ ). Tumor size had been used in evaluation for pre-treatment TNM staging According to the COG-STS Committee's,

Of embryonal types $(n=12), 3$ patients had botryoid subtype of embryonal. Interestingly, the pleomorphic subtype was not found in this study. The histological subtype classification used in this study was based on the newest classification from WHO (2013).

More than half of the patients (57\%) had a tumor in an unfavorable site. Tumor located in the facial, orbital, nose, lip, and neck were included in the head and neck group. Tumor in upper extremity was more dominant than lower extremity that counted in $75 \%$ of the patients. Tumor in extremities was most common in the age group 10-15 years. Tumor located in the intraabdominal and vertebrae were included in the trunk group while tumor in the bladder, testis, vulva, and vagina was included in the urogenital group.

Only 25 out of 30 children's staging were identified. Of the 27 patients in whom treatment was initiated, the vast majority of the patients were treated with chemotherapy (83\%) where $47 \%$ of them with chemotherapy only and the rest with combination therapy. Around $67 \%$ of children who had surgical resection had tumors $>5 \mathrm{~cm}$. Three patients died before giving any kind of therapy in the care center. Pre-treatment staging used a modified TNM system based on the primary site, either favorable or unfavorable site.

\section{Discussions}

The results of this study showed more male (54.05\%) Rhabdomyosarcoma (RMS) is the most common soft-tissue sarcomas (STS) in children, included in the top 10 most common malignancies. Nevertheless, RMS incidence is relatively rare. ${ }^{7}$ In our center, there were only 30 RMS children during the 4 years period. The median age is 5 years old or about 59.5 months. This finding is similar to a study conducted in China $^{13}$ showing a median age of 61.5 months. In our study, most of the children (63\%) aged below 10 years and the highest age-adjusted incidence in the category of aged 1-5 years, similar to a various studies published earlier. ${ }^{6,7}$ Male patients outnumbered female patients with $\mathrm{M}: \mathrm{F}$ ratio $1.3: 1$. This finding also similar to the previous studies, that consistently showed a gender differential incidence of child health cancer worldwide with M:F ratio around $1.2: 1 .^{13,14}$

Swelling or lump is the main presenting symptom in this study. This result is in accordance with a study in Sub-Saharan Africa ${ }^{10}$ showing that all the children have presented with swellings, while more than half of the patients in Romania ${ }^{1}$ presented with swelling in varying sites. Some of the additional symptoms may result from the compression of local structures by the masses. ${ }^{8}$ This often vague and non-specific symptom may cause a delay in the admission of these children to the care center, leading to the advanced stage of the disease. ${ }^{10}$

The diagnosis of RMS usually has been preferably performed by direct open biopsy. ${ }^{8}$ An adequate biopsy sample is critical for an accurate biopsy, hence, fine needle aspiration biopsy (FNAB) is not recommended However, in this research study, an open biopsy was conducted to about $63 \%$ of the patients and the rest used FNAB similar to another study in Jakarta. ${ }^{6}$ The FNAB is a fast, highly safe, and effective method, therefore, FNAB is still used for the detection of carcinoma. FNAB is less expensive than open biopsy, does not require anesthesia, and also less traumatic, hence, it 
could save more time and money, and also more convenient for the patient. Nonetheless, open surgical biopsy provided a more definitive diagnostic histology than FNAB. ${ }^{15}$

A histologic subtype can be observed from biopsy samples microscopically. The most common subtype in this study is embryonal RMS, followed by alveolar and spindle cells. This result is quite similar to the findings from East Egypt and China that showed embryonal is the most frequent histopathologic subtype followed by alveolar and spindle cell though with quite different numbers. ${ }^{16,17}$ Plemorphic subtype has not been found in this research because it is really rare to occur in children and more common in adult patients.18 Interestingly, there are patients with an unknown subtype of RMS. This is evidence that some tumors can not be characterized by the pathologist. ${ }^{18}$

The size of the tumor can only be party assessed since the tumor is in the unreachable location. The majority of the patients had tumors $>5 \mathrm{~cm} .{ }^{1,17}$ Around $70 \%$ of the patients with tumor $>5 \mathrm{~cm}$ passed away. This high mortality may be caused by patient delays in seeking medical care that is influenced by socioeconomic status and education degree of the parents. This delay could slow down the establishment of the diagnosis which is proven to be related to the increasing size of the tumor. ${ }^{9}$ Education for the community and medical personnel is important to increase alertness for RMS to further improve the prognosis.

Rhabdomyosarcoma may occur in any anatomic location of the body. In this study, we have identified the most frequent primary sites are head and neck followed by extremities, then the trunk and urogenital tract as known. ${ }^{19}$ However, another study in China has shown different primary sites with the genitourinary system is the most frequent site, followed by head and neck, then extremities. ${ }^{17}$ These differences may be caused by age range prevalent in each study.

In this study, only 27 out of 30 patients were given treatment. Almost half of the patients $(47 \%)$ only had chemotherapy while $33 \%$ had chemotherapy combined with surgical resection. Similar to the study in Jakarta, only $41 \%$ had chemotherapy, while $39 \%$ had a combination of chemotherapy and surgical resection. 6 The majority of the patients who came to the care center were in the advanced stages. ${ }^{1,6,20}$ This may be related to the low socioeconomic status, educational background of the parents, and other causes. Unfortunately, in this study, neither socioeconomic status nor education degree has been noted. This limitation may lead to further exploration.

To conclude, children with a tumor in the head and neck region should be suspected as rhabdomyosarcoma. There are various clinical characteristics similar to the results of previous studies around the globe. Interestingly, late presentation is commonly seen; therefore, public health awareness and promotion are urgently needed.

\section{References}

1. Diaconescu S, Burlea M, Miron I, Aprodu S, Mihăilă D, Olaru C, et al. Childhood rhabdomyosarcoma. Anatomo-clinical and therapeutic study on 25 cases. Surgical implications. Rom J Morphol Embryol. 2013;54(3):531-37.

2. Hessissen L, Kanouni L, Kili A, Nachef MN, El Khorassani M, Benjaafar N, et al. Pediatric rhabdomyosarcoma in Morocco. Pediatr Blood Cancer. 2010;54(1):25-28.

3. Alex RA, Nayak DR, Devaraja K, Reddy NA, Singh R, Shetty S. Head-and-neck rhabdomyosarcoma: Our experience. Ann Indian Acad Otorhinolaryngol Head Neck Surg. 2018;2(1):1-4.

4. Hawkins DS, Spunt SL, Skapek SX, Committee COG Soft Tissue Sarcoma Committee. Children's Oncology Group's 2013 blueprint for research: Soft tissue sarcomas. Pediatr Blood Cancer. 2013;60(6):1001-08.

5. Rini AT, Edhy K, Gatot D, Windiastuti E, Ciputra Y. Rabdomiosarkoma pada anak: gambaran klinis di 2 institusi. Indonesian Journal of Cancer. 2008;2(2):55-59.

6. Gatot D, Windiastuti E. Rabdomiosarkoma pada anak: luaran klinis pada pasien yang mendapat terapi. Indonesian Journal of Cancer. 2011;5(2):83-87.

7. Perez EA, Kassira N, Cheung MC, Koniaris LG, Neville HL, Sola JE. Rhabdomyosarcoma in children: a SEER population based study. J Surg Res. 2011;170(2):e243-e51.

8. Hayes-Jordan A, Andrassy R. Rhabdomyosarcoma in children. Curr Opin Pediatr. 2009;21(3):373-78.

9. Ferrari A, Miceli R, Casanova M, Meazza C, Favini F, Luksch R, et al. The symptom interval in children and adolescents with soft tissue sarcomas. Cancer. 2010;116(1):177-83.

10. Ibikunle AA, Taiwo AO, Braimah RO, Abdullahi K, Malami UA. Orofacial rhabdomyosarcoma: A 5-year 
clinicopathologic study from Sub-Saharan Africa. Clin Cancer Invest J. 2018;7(2):56.

11. Crist WM, Anderson JR, Meza JL, Fryer C, Raney RB, Ruymann FB, et al. Intergroup rhabdomyosarcoma study-IV: results for patients with nonmetastatic disease. J Clin Oncol. 2001;19(12):3091-102.

12. Rudzinski ER, Anderson JR, Hawkins DS, Skapek SX, Parham DM, Teot LA. The World Health Organization classification of skeletal muscle tumors in pediatric rhabdomyosarcoma: a report from the Children's Oncology Group. Arch Pathol Lab Med. 2015;139(10):1281-87.

13. Li M, Bian $X$, Jing $R$, Zhang A, Sun N, $\mathrm{Ju} \mathrm{X}$, et al. Retrospective analysis of rhabdomyosarcoma (RMS) in children in a single center. Thorac Cancer. 2018;9(9):1180-84.

14. Dorak MT, Karpuzoglu E. Gender differences in cancer susceptibility: an inadequately addressed issue. Front Genet. 2012;3:268.

15. 15. Nassar A. Core needle biopsy versus fine needle aspiration biopsy in breast-a historical perspective and opportunities in the modern era. Diagn Cytopathol. 2011;39(5):380-88.

16. Badr M, Al-Tonbary Y, Mansour A, Hassan T,
Beshir M, Darwish A, et al. Epidemiological characteristics and survival studies of rhabdomyosarcoma in East Egypt: a five-year multicenter study. ISRN Oncol. $2012 ; 2012$.

17. MaX,HuangD, Zhao W,Sun L, Xiong H,Zhang Y, etal.Clinical characteristicsand prognosis of childhood rhabdomyosarcoma: a tenyear retrospective multicenter study. Int J Clin Exp Med. 2015;8(10):17196.

18. Sultan I, Qaddoumi I, Yaser S, RodriguezGalindo C, Ferrari A. Comparing adult and pediatric rhabdomyosarcoma in the surveillance, epidemiology and end results program, 1973 to 2005: an analysis of 2,600 patients. J Clin Oncol. 2009;27(20):339197.

19. Bansal D, Das A, Trehan A, Kapoor R, Panda NK, Srinivasan R, et al. Pediatric rhabdomyosarcoma in India: A singlecenter experience. Indian Pediatr. 2017;54(9):735-38.

20. Akyüz C, Sarı N, Yalçın B, Varan A, Kutluk T, Büyükpamukçu M. Long-term survival results of pediatric rhabdomyosarcoma patients: a single-center experience from Turkey. Pediatr Hematol Oncol. 2012;29(1):38-49. 